AperTO - Archivio Istituzionale Open Access dell'Università di Torino

\title{
Health practitioners' implicit and explicit attitudes predict absenteeism and extra work
}

\section{This is the author's manuscript}

Original Citation:

Availability:

This version is available http://hdl.handle.net/2318/140249

since 2015-09-13T14:55:04Z

Published version:

DOI:10.1080/01973533.2013.764300

Terms of use:

Open Access

Anyone can freely access the full text of works made available as "Open Access". Works made available under a Creative Commons license can be used according to the terms and conditions of said license. Use of all other works requires consent of the right holder (author or publisher) if not exempted from copyright protection by the applicable law. 
Health practitioners’ implicit and explicit attitudes towards drug addicts predict absenteeism and extra work

\begin{abstract}
We analyzed the correspondence between implicit and explicit attitudes of health care practitioners working with drug addicts as a function of years of professional experience, and its relation with important organizational outcomes. We initially showed that the attitudes of practitioners working in institutions with drug addicts $(n=27)$ and those of volunteers working in these institutions ( $n=30)$ were more positive than those of laypeople $(n=30)$. Consistent with the hypothesis that implicit-explicit attitude inconsistency is unpleasant and people struggle to resolve it, practitioners' implicit-explicit consistency increased with years of experience. Analyses focused on practitioners showed that for practitioners self-reporting positive attitudes, negative implicit attitudes led to increased absenteeism and decreased voluntary extra work. For practitioners selfreporting negative attitudes, positive automatic associations had similar effects. Strengths, limitations, and possible extensions of this research are discussed.
\end{abstract}

Keywords

Implicit attitudes; Stigma; Prediction of behavior; Attitude Inconsistency, Counterproductive work behaviors 
Health practitioners and social workers are often required to deal with stigmatized people, like those suffering from mental illness, drug addiction, and overweight. Their bias toward the categories these people belong to has important consequences, because it negatively affects clinical decisions (Garb, 1997) and treatment quality (Irwin, 2007; Wahl \& Aroesty-Cohen, 2010). In this field of investigation most of the research has been based on explicit attitudes-i.e., on controlled evaluations of the category of interest assessed with questionnaires. However, to get a complete picture of evaluative judgments, implicit attitudes - the more spontaneous and automatic affective reactions toward the same category—should also be taken into consideration. Indeed, explicit and implicit attitudes are sometimes unrelated (Dovidio, Kawakami, \& Beach, 2001; Greenwald, McGhee, \& Schwartz, 1998; Nosek, 2005; Teachman, Gapinski, Brownell et al., 2003) and often predict different aspects of behaviour (Perugini, Richetin, \& Zogmaister, 2010).

Supporting the claim of the importance of health practitioners' implicit attitudes, two vignette studies have revealed the importance of health practitioners' implicit attitudes. Physicians’ automatic racial prejudice, but not their self-reported judgments, biased their simulated diagnostic and prognostic decisions (Green, Carney, Pallin, et al., 2007); moreover, their implicit negative attitudes predicted over-diagnosis (Peris, Teachman, \& Nosek, 2008). Furthermore, von Hippel, Brener, and von Hippel (2008) showed that both implicit and explicit prejudice towards injecting drug users predicted drug and alcohol nurses’ intentions to change jobs. However, at present no study has been performed among health care practitioners to examine the causes and consequences of the interplay between their explicit and implicit attitudes toward the social groups they work with. We aimed to fill this gap by focusing on practitioners working with drug addicts, a highly stigmatized category (Cape, 2003; Corrigan, Kuwabara, \& O’Shaughnessy, 2009).

Based on social cognitive models, like the Associative-Propositional Evaluation (APE) model (Gawronski \& Bodenhausen, 2006), we define implicit attitudes as affective reactions activated automatically by an object. Implicit attitudes depend on the presence of associative links between object and evaluation and are typically assessed through cognitive measures like the Implicit 
Association Test (IAT, Greenwald, McGhee, \& Schwarz, 1998). The valence of automatic reactions to members of a social category depends on various factors, including the representation of the category conveyed by the dominant culture (Devine, 1989), early contact with members of the category (Rudman, 2004; Rudman, Phelan, \& Heppen, 2007), and associations between oneself and a member of the category (Phills, Kawakami, Tabi, \& Inzlicht, 2011). By explicit attitudes, on the other hand, we mean more controlled evaluations of the object of interest (see Gawronski \& Bodenhausen, 2006). Explicit attitudes are typically assessed through self-report questionnaires. Explicit and implicit attitudes are often consistent with each other. However, individuals can simultaneously hold contrasting implicit and explicit attitudes (Hofmann, Gawronski, Gschwendner, Le, \& Schmitt, 2005). Inconsistencies between implicit and explicit attitudes are directly tackled in the most recent social cognitive models of attitudes, such as the Meta-Cognitive Model (Petty, Briñol, \& DeMarree, 2007), the System of Evaluation Model (Rydell \& McConnell, 2010), and (as already mentioned) the APE model.

For instance, based on the APE model, an inconsistency between implicit and explicit attitudes can appear when an individual holds a negative implicit attitude toward a certain social group, but rejects it at the explicit level because it is at odds with other relevant cognitive contents (e.g., beliefs or values). In particular, when an individual mindfully evaluates people suffering from drug addiction, a negative automatic affective reaction can take the form of the proposition "I do not like them”. However, the propositional meaning of the affective reaction (i.e., "I do not like them”) may contrast with other propositions that the individual holds and considers to be relevant for the evaluation (e.g., “They are fragile individuals, who often have had very difficult life experiences”). In order to overcome the incongruence, the individual can reject the propositional meaning of the affective reaction as invalid, and substitute it with a positive explicit evaluation of the target. Alternatively, he or she can find additional propositions (e.g., "Other people have tackled similar difficulties in their life without falling into addiction”) to get over the incongruence and accept the propositional meaning of the negative automatic reaction. Of course, also in the opposite case- 
when the implicit attitude is positive- the evaluation can be accepted and endorsed at the explicit level or declined and substituted with a more neutral or negative explicit evaluation. In sum, by inconsistency we mean the discordance between explicit and implicit attitudes (i.e., implicit ambivalence; Petty \& Briñol, 2009). The most obvious form of such inconsistency occurs when the individual holds attitudes that are opposite to each other in valence. Less extreme forms of inconsistency occur when the individual holds attitudes of the same valence, but with different levels of extremity.

There is a scarce but growing corpus of evidence showing that behaviors are influenced by the inconsistency between implicit and explicit attitudes. Roccato and Zogmaister (2010) showed that inconsistent explicit and implicit political preferences lead to delayed voting decisions, and Perugini (2005) showed that consistency between implicit and explicit attitudes toward smoking fostered the probability of smoking.

Moreover, there is some evidence that inconsistency between explicit and implicit attitudes leads to unpleasant feelings. Olson and Fazio (2007) found the discrepancy between non-Black participants' implicit racial attitudes and explicit evaluation of a Black individual to be related to the frequency of nonverbal behaviors symptomatic of discomfort in social interactions during a speech regarding the Black individual, while Petty, Briñol, and co-workers (2009; Briñol, Petty, \& Wheeler, 2006) and Rydell and McConnell (2010; see also Rydell \& Durso, 2012) argued and provided empirical evidence that inconsistencies between implicit and explicit cognitions elicit feelings of tension or discomfort and that people attempt to use psychological strategies to reduce them. Rydell and McConnell (2010) argued that the frequent experience with an attitude object evoking incongruent implicit and explicit attitudes should increase the accessibility of the negative feelings and tensions, leading one to make special efforts to reduce the discrepancy. Thus, one should expect behavioral outcomes related to distress to be particularly relevant when the object of the attitude is central for the individual, for example, when it is an essential aspect of his or her own job. 
The inconsistency between implicit and explicit attitudes can be operationalized in at least three different ways (see Zogmaister, 2011). The simplest strategy, dichotomous classification of participants, consists of two steps: After dichotomising both implicit and explicit attitudes based on the estimate of a neutral point, participants whose implicit and explicit attitudes are both classified as positive, or both as negative, are considered to be “consistent”, and participants having negative implicit attitudes and positive explicit attitudes, or vice-versa, are considered to be "inconsistent" (Roccato \& Zogmaister, 2010).

Another strategy consists of computing the inconsistency between implicit and explicit attitudes as the absolute value of the difference between the standardized explicit and implicit attitude scores (Briñol et al., 2006; Kehr, 2004; Rydell, McConnell, \& Mackie, 2008). Since the resulting index contains no indication of the direction of the discrepancy, a further index of direction must be considered in the analysis.

The third strategy is linear regression: The outcome of interest is regressed on the implicit attitude score, the explicit attitude score, and their interaction (Aiken \& West, 1991). With this strategy, no computation of additional indexes is required beyond the index of implicit and explicit attitudes. This is the strategy we used in the present work (see below).

The current study

Our main aim was to extend the existing literature on the interplay between implicit and explicit attitudes in an organizational framework. Based on the literature above, we investigated the consequences of implicit-explicit attitude inconsistency for absenteeism and avoidance of voluntary extra work. Absenteeism — which allows people to temporarily escape the unpleasant experiences related to their profession and recover mentally, with the side-effect of transmitting the costs to coworkers and the organization and of making organizations waste millions of dollars each year (Hausknecht, Hiller, \& Vance, 2008)—correlates with work stress (e.g., Hystad, Eid, \& Brevik, 2011), burnout (Lambert, Hogan, \& Altheimer, 2010; Ybema, Smulders, \& Bogers, 2010) and guilt 
stemming from negative attitudes toward clients (Gil-Monte, 2008). Extra work is positively related to job satisfaction (Bakker, Schaufeli, Leiter, \& Taris, 2008; Judge \& Chandler, 1996).

Generally speaking, our basic hypothesis was that the overall unease caused by inconsistency between implicit and explicit attitudes is an important determinant of these behaviors. More specifically, we investigated the impact of length of direct experience on implicit-explicit attitude in/consistency and we analyzed the effects of such in/consistency on absenteeism and non-paid extra work.

To understand whether practitioners' attitudes were congruent with the common societal view that portrays drug addicted individuals in negative terms, we first compared the implicit and explicit attitudes toward drug addicts of a sample of practitioners working in residential institutions with those of a sample of volunteers working in the same institutions and with those of a sample of people who did not work or volunteer with drug addicts. The cultural view of drug addicted people is negative (Cape, 2003; Corrigan et al., 2009), while the effects of individual encounters are presumably more variable. Moreover, it is plausible that many volunteers and practitioners define part of their self-concept in terms of their work with people suffering with drug addiction and therefore form an association between the self-concept and drug addiction. Furthermore, recent studies showed that even negative concepts, when they are associated with the self, can acquire implicit positivity (Perugini, Richetin, \& Zogmaister, in press). Therefore we hypothesized that (a) practitioners and volunteers would show similar attitudes toward drug addicts, because they shared daily contact with the target category and presumably chose their professional or voluntary activity also based on a substantially positive view of the target category (HP1a); and (b) both practitioners and volunteers would show less negative attitudes toward drug addicts than the subsample of laypeople (Schulze, 2007; Wahl \& Aroesty-Cohen, 2010) (HP1b).

Our analysis of the direct relationship between implicit and explicit attitudes and our dependent variables was exploratory. On the one hand, based on the negative relationship found by von Hippel and colleagues (2008) between both implicit and explicit attitudes and intention to quit 
one's job, it was reasonable that practitioners with more negative implicit and/or explicit attitudes toward drug addicts would abstain from work more often and would less frequently perform extra work. On the other hand, in contrast to intentions to quit one's job, which are plausibly the result of a deliberative reasoning process involving attitudes and cognitions related to the most relevant aspects of one’s job, absenteeism and voluntary extra work probably have an impulsive basis (Barmby, Sessions, \& Treble, 1994; Scoppa, 2010). Therefore, we expected them to be more strongly related to job dissatisfaction and unease. Thus, we neither ruled out nor strongly hypothesized a direct relationship between implicit and explicit attitudes, on the one hand, and absenteeism and extra work, on the other hand.

People use strategies to reduce discrepancies between implicit and explicit attitudes toward a relevant routine object, such as increasing relevant information processing (Petty \& Briñol, 2009; Rydell et al., 2008). Therefore we expected inconsistency between implicit and explicit attitudes to be reduced over time and for this reason we hypothesized a positive relation between years of experience with drug addicts and consistency between implicit and explicit attitudes among practitioners (Petty \& Briñol, 2009; Rydell et al., 2008) (HP2). ${ }^{1}$ Finally, because of the positive association between absenteeism and unpleasant feelings (Yaniv, 1995; Ybema et al., 2010) and the negative association between extra work and unpleasant feelings (Yaniv, 1995), we expected inconsistency between explicit and implicit attitudes towards drug addicts to foster practitioners’ absenteeism (HP3a) and reduce their days of nonpaid extra work (HP3b).

\section{Pilot study}

Before undertaking the main study, we performed a pilot study to check the psychometric properties of our implicit and explicit measures, which we prepared ad hoc for the purposes of the present research.

Participants and Procedure

Fifty-seven university students were recruited through the University of Milano-Bicocca subject management pool and received partial course credit for their participation. Through the 
world wide web we administered to respondents an ad hoc 15-item adaptation of the factor "Warmth, liking, and interest in contact with people with personality disorders" of the Attitudes Toward Personality Disorders Questionnaire (Bowers \& Allan, 2006) as a measure of explicit attitudes and the Single-Category IAT (SC-IAT, Karpinski \& Steinman, 2006), a modified version of the Implicit Association Test (IAT, Greenwald et al., 1998) that does not require a comparison category, to measure participants' implicit attitudes toward drug addicts. In the questionnaire participants reported how often they experienced emotions related to patients with drug addictions (e.g.: "I feel patient when caring for patients who are addicted to drugs”) choosing among the response options $0=$ never, 1 = rarely, 2 = often, and 3 = always". ${ }^{2}$ We asked participants to think about the category in general and avoid focusing on relationships with specific people.

In the SC-IAT participants were presented a series of stimuli on a computer screen: 21 positively valenced words, 21 negatively valenced words (e.g., the Italian equivalents of happiness, rainbow, and love, and of tragedy, vomit, and hell, respectively), and 5 two-word phrases referring to people with drug addictions (the Italian equivalents of drug user, heroin user, substance abuser, drug addict, and drug addiction (“consumatore di droghe”, “consumatore di eroina”, “consumatore di stupefacenti”, “tossicodipendente” and “tossicodipendenza”).

We structured the SC-IAT into four blocks (see Table 1). In the first and the third blocks participants were familiarized with the test; the second and the fourth blocks measured their implicit attitudes toward drug addicts. In the second block, participants had to press a key when presented with a positive word or a word that referred to people with drug addiction and another key when presented with a negative word; in the fourth block, participants had to press a key when presented with a positive word, and another key when presented with a negative word or a word that referred to drug addiction. Participants were randomly assigned to one of the four experimental conditions resulting from the counterbalancing of the order of the SC-IAT and the questionnaire and the counterbalancing of the blocks within the SC-IAT. 
SC-IAT. Following Karpinski \& Steinman (2006), we computed the SC-IAT score as the difference between the mean latency in the block that associated drug addicts with the negative category and the block that associated drug addicts with the positive category, divided by the overall $S D$ : negative values indicated negative attitudes toward people with drug additions. The reliability of the SC-IAT was $\alpha=.750$, On average, participants displayed a negative implicit association toward the target category, significantly different from zero, $M=-.20, S D=.28, t(56)=5.32, p<.001, d=$ .71 , with observed values ranging between $\min =-.73$ and $M a x=.42$. An ANOVA indicated that SC-IAT scores were not influenced by the order of the blocks within the SC-IAT, nor by the reciprocal order of SC-IAT and questionnaire, either alone or in interaction, all $p$ 's $>.09$.

Explicit attitude. We computed the average of responses to the 15 items of the explicit measure ( $\alpha=.857$, after appropriate reverse scoring). Possible values ranged between 0 and 3 . Higher values indicated more positive attitudes toward drug addicts. Observed values ranged from $\min =.27$ to Max $=2.00$, with a mean value of $M=1.29, S D=.41$, which was significantly lower than 1.5 , which was the theoretical midpoint of the scale, $t(56)=3.91, p<.001, d=.51$. An ANOVA indicated that the explicit attitude score was not influenced by the order of administration of the measures, $p$ 's > .23. The correlation between the index of implicit and explicit attitude was non-significant, $r=.09, p$ $=.49$.

Thus, the reliability of the explicit questionnaire was good, and the reliability of the SC-IAT was acceptable, in the usually observed range for the SC-IAT (Karpinski \& Steinman, 2006). Moreover, the reliability of the SC-IAT was probably a conservative estimate, because the administration of the measure on the internet did not allow for the full control of important conditions required for implicit measures, such as the absence of noise and other sources of distraction. The presence of negative implicit and explicit attitudes toward the category of drug addicts was confirmed. More importantly, the absence of a correlation between the two measures indicated that they tapped different aspects of attitudes toward drug addicts. 


\section{Participants}

Thirty laypeople, 30 volunteers (13 of whom were former drug addicts) and 27 practitioners working daily with drug addicts participated in our study (total $N=87,48.3 \%$ women, mean age $=$ 39.94, $S D=12.85)$. Participants lived and worked in Torino, Italy. Data were collected in laypeople’s homes and in the volunteers' and practitioners' workplace. The three groups were equivalent in terms of gender, $\chi^{2}(4)=7.316, p=.12$, and age, $F(2)=.098, p=.91$; Table 2 shows their demographic characteristics.

\section{Procedure}

Participants were administered the SC-IAT and the 15-item explicit questionnaire on attitudes toward drug addiction pre-tested in the Pilot Study. The questionnaire we administered to our practitioners included an additional section, asking them to report (a) the number of days they abstained from work and the number of times they voluntarily did extra work in the six months before their participation in our research; and (b) length of experience with drug addicts, operationalized as number of years elapsed since they had begun their work with patients suffering from drug addiction. We did not assess absenteeism, extra work, and length of experience with people suffering from drug addiction among volunteers, in that these variables were fuzzy to operationalize in this subsample. Moreover, volunteers were a highly heterogeneous group, with approximately half of them being former members of the stigmatized category. Former membership might strongly influence the dynamics of attitudes (e.g., Brown, 2010).

Participants were randomly assigned to one of the four experimental conditions resulting from the counterbalancing of the order of the SC-IAT and the questionnaire, and the counterbalancing of the blocks within the SC-IAT. The reliability of the questionnaire was $\alpha=.816$, and the reliability of the SC-IAT was $\alpha=.905$. Explicit attitudes did not vary as a function of either counterbalancing factor, both F's $(1,84)<.07$, p's $>.79$. The order of administration of the measures did not influence the SC-IAT score, $F(1,83)=.41, p=.52$; however, the order of the SC-IAT blocks did, $F(1,84)=6.14, p=.02, \eta_{p}^{2}=.07:$ SC-IAT scores were higher for the subsample who completed the 
block that associated drug addiction with negative valence before the block in which drug addiction was associated with positive valence. We controlled such effect using as a measure of implicit attitude the standardized residual of the regression of SC-IAT scores on order of the SC-IAT blocks. ${ }^{3}$

\section{Results}

Consistent with our HP1a and our HP1b, two a priori comparisons indicated no significant differences between practitioners' and volunteers' implicit, $t(84)=.29, p=.77, d=0.08$, and explicit, $t(84)=1.49, p=.14, d=.39$, attitudes toward drug addicts. Lay participants showed more negative implicit, $t(84)=2.33, p=.02, d=0.54$, and explicit, $t(84)=9.92, p<.01, d=2.24$, attitudes toward drug addicts than practitioners and volunteers (see Table 3 for the corresponding descriptive statistics). The status of former drug addicts did not significantly affect either the explicit or the implicit attitudes of volunteers, both $t \mathrm{~s}<1$, both $p s>$.62, both $d \mathrm{~s}<0.20$.

To address the role played by length of experience with drug addicts in the consistency between explicit and implicit attitudes, we conducted a multistep regression, in which we regressed the explicit attitude on the implicit attitude score (Step 1), adding years of experience with drug addicts in Step 2, and the interaction between implicit attitude and experience in Step 3. Table 4 shows that the implicit attitude, when considered alone, was significantly related to the explicit attitude (Step 1). The measure of length of experience did not significantly add to the prediction (Step 2), but the length of experience with the stigmatized group moderated the relationship between implicit and explicit attitudes (Step 3).

Figure 1 shows that, in line with our HP2, the consistency between implicit and explicit attitudes was positively related with the number of years of experience in the profession. We compared the relationship between implicit and explicit attitudes among participants who had the minimum (1 year), mean (10 years) and the maximum (26 years) length of experience. Among participants who had the minimum length of experience, there was no significant relationship between the implicit and the explicit attitudes, $b=-.06, p=.66$. The relationship became significant 
for participants with the mean, $b=.21, p<.01$, and with the maximum experience, $b=.70, p<.01$. Age did not explain or modify this effect.

To test the influence exerted by the incongruence between explicit and implicit attitudes on absenteeism and extra work, we conducted two multistep regressions, in which we regressed the two criteria on sex and age, used as control variables (Step 1), adding explicit and implicit attitude scores (Step 2), and the interaction between the implicit and explicit attitude scores (Step 3). Table 5 shows that neither explicit nor implicit attitudes exerted additive effects on absenteeism and extra work. However, the models tested at Step 3 were significant for both criteria, $p$ 's $<.04$. The level of in/congruence between implicit and explicit attitudes influenced both absenteeism and extra work. Following Cohen, Cohen, West and Aiken (2003) we investigated the interaction effect considering the values of the mean minus and plus one standard deviation as, respectively, low (unfavourable) and high (favourable) levels of the attitudes. Figure 2 shows that the incongruence between implicit and explicit attitudes was associated with more absenteeism and less extra work. Thus, consistent with HP3a and HP3b, practitioners' organizational behaviour was influenced by the interplay between implicit and explicit attitudes. More specifically, for participants with a negative implicit attitude toward drug addicts, the increase of positivity of the explicit attitude - which indicated inconsistency between implicit and explicit attitudes - was associated with an increase in the predicted number of days of absence (Figure 2, upper part, solid line) and with a decrease in the predicted number of days of extra work (Figure 2, lower part, solid line). Conversely, for participants with a positive implicit attitude, the increase of positivity of the explicit attitude - which indicated consistency - predicted a decrease in absenteeism (Figure 2,upper part, dotted line) and an increase in the number of days of extra work (Figure 2,lower part, dotted line). In sum, consistency was associated with voluntary extra work; conversely, inconsistency was associated with absenteeism. ${ }^{4}$

\section{Discussion}


Employee engagement is usually predicted using explicit variables, such as perceived resources and perceived demands (e.g. Crawford, LePine, \& Rich, 2010). Building on recent social cognition research (e.g. Rydell, McConnell, \& Mackie, 2008; Petty \& Briñol, 2009; Rydell \& McConnell, 2010), our aim was to further develop this field of study by focusing on the links between explicit and implicit constructs. We showed that the consistency of implicit and explicit attitudes toward drug addicts increased as a function of the time spent with this stigmatized category and was related to two positive organizational outcomes: more frequent occurrence of nonpaid extra work and less frequent occurrence of absenteeism. Thus, the interplay between explicit and implicit constructs, but not their absolute level, was related to organizational productivity and performance.

According to the literature, many costly organizational behaviours, among which are those we studied, can be a consequence of work stress (e.g. Hystad, Eid, \& Brevik, 2011). Thus, our results indirectly suggested that among social workers, inconsistency between explicit and implicit attitudes towards the people they work with should be considered a stress factor. Moreover, they showed that such inconsistency should be considered as more stressful than consistently holding negative explicit and implicit attitudes toward the category of people social workers work with. This is in line with the psychological literature on the cognitive consequences of holding inconsistent explicit and implicit attitudes, which shows that implicit-explicit inconsistency is associated with an uncomfortable state of negative arousal (Rydell et al., 2008; Rydell \& Durso, 2012) and individuals enact cognitive strategies aimed at reducing it (Petty \& Briñol, 2008).

In our research neither implicit nor explicit attitudes towards drug addicts directly influenced the two organizational behaviours we analyzed, while in von Hippel and colleagues' (2008) study implicit and explicit prejudice towards injecting drug users significantly predicted drug and alcohol nurses' intentions to change jobs. Some important differences may explain the differences in results. Indeed, Von Hippel's and our dependent variables, beyond their commonalities (mainly the negative effects they exert on organizations’ efficacy and efficiency: see Knudsen, Ducharm, \& Roland, 2009) have a different status. On the one hand, like other behaviour intentions, intentions to change 
jobs should be considered as the outcome of substantially deep information elaboration and as involving somewhat deliberate planning (Ajzen, 1988; Strack \& Deutsch, 2004). Indeed, according to the literature, intentions to change jobs are powerful predictors of freely chosen turnover (van Breukelen, van der List, \& Steensma, 2004). On the contrary, absenteeism and avoiding voluntary extra work should be considered shirking behaviours (Barmby et al., 1994), closer to what clinical psychologists label as acting-out than to deliberate planning, especially in countries, such as Italy, in which workers are typically entitled to receive a sickness subsidy if they are experiencing ill health (Scoppa, 2010).

In coming years, the growth of the service sector and the competition among organizations working in the social services field will likely amplify organizational demands on practitioners’ emotional labour and self-control (Diestel \& Schmidts, in press). Thus, it is far from surprising that the bulk of stress-reduction interventions have been developed to train employees in regulating psychological states when coping with stressful work events (Bond \& Bunce, 2000). In the meanwhile, there are numerous programs aimed at combating stigmatization on a large scale; indeed, the elimination of stigma is one of the main goals of the World Health Organization (WHO, 2005). This study highlighted the idea that these sets of interventions should tackle both consciously expressed attitudes and automatic affective reactions toward target groups.

We believe that the major strengths of the present work are (1) the investigation of attitudes toward a stigmatized category in the field, with a special focus on the consequences of these attitudes for two aspects of organizational behaviour that affect the assistance that can be provided to members of the category; and (2) the focus on the interplay between explicit and implicit attitudes, both from the viewpoint of the relationship between consistency and length of experience, and from the effects of consistency on behaviour.

The relatively low number of participants was a quasi-necessary disadvantage we had to accept because of the difficulty in reaching members of our target population. We expected a higher level of consistency between implicit and explicit attitudes in practitioners with a higher number of years 
of experience as a consequence of enhanced mental elaboration of the target category due to the repeated contacts with its members. An alternative explanation of this effect in terms of cohort effects was ruled out because participants' age did not affect the consistency between implicit and explicit attitudes, but subsequent studies would be welcome, to further investigate this and other explanations of the observed effect.

Another useful expansion of the present results would be to investigate the consequences of attitude (in)congruency for organizational behaviour of workers in other domains characterized by potentially inconsistent attitudes. Furthermore, although we hypothesize that the observed effects of inconsistency on absenteeism and extra work are mediated by inconsistency-related discomfort, this mediating effect was not investigated in the present study and future research should address this issue. Finally, searching for moderators of the relations we analyzed will be germane. In particular, building on Bowling and Eschleman (2010), who showed that the relation between work stressors and counterproductive work behaviours is stronger among employees low in conscientiousness, it could be fruitful to analyze the role of personality. Moreover, building on De Hoog and Den Hartog (2009), who showed that autocratic leaders foster burnout, especially among neurotic employees, the impact of the leadership style in the organization on the consequences of attitude inconsistency could also be studied. 


\section{References}

Ajzen, I. (1988). Attitudes, personality, and behavior. Chicago, IL: Dorsey.

Bakker, A. B., Schaufeli, W. B., Leiter, M.-P., \& Taris, T. W. (2008). Work engagement: An emerging concept in occupational health psychology. Work \& Stress, 22, 187-200. doi: $10.1080 / 02678370802393649$

Barmby, T., Sessions, J., \& Treble, J. G. (1994). Absenteeism, efficiency wages, and shirking. Scandinavian Journal of Economics, 96(4), 561-566.

Bluemke, M., \& Friese, M. (2008). Reliability and validity of the Single-Target IAT (ST-IAT): Assessing automatic affect toward multiple political groups. European Journal of Social Psychology, 38, 977-997. doi: 10.1002/ejsp.487

Bond, F. W., \& Bunce, D. (2000). Mediators of change in emotion-focused and problem-focused worksite stress management interventions. Journal of Occupational Health Psychology, 5, 156-163. doi:10.1037/1076-8998.5.1.156

Bowers, L., \& Allan, T. (2006). The attitude towards disorder personality questionnaire: Psychometric properties and results. Journal of Personality Disorders, 20, 281-293. doi: 10.1521/pedi.2006.20.3.281

Bowling, N. A., \& Eschleman, K. J. (2010). Employee personality as a moderator of the relationships between work stressors and counterproductive work behavior. Journal of Occupational health Psychology, 15, 91-103. doi: 10.1037/a0017326

Brown, R. (2010). Prejudice: Its social psychology (2nd ed.). Oxford: Blackwell.

Briñol, P., Petty, R. E., Wheeler, S. C. (2006). Discrepancies between explicit and implicit selfconcepts: Consequences for information processing. Journal of Personality and Social Psychology, 91, 154-170. doi: 10.1037/0022-3514.91.1.154

Cape, G. S. (2003). Addiction, stigma and movies. Acta Psychiatrica Scandinavica, 107, 163-169. doi: 10.1034/j.1600-0447.2003.00075.x 
Cohen, J., Cohen, P., West, S. G., \& Aiken, L. S. (2003). Applied multiple regression/correlation analysis for the behavioural sciences (3rd ed.).Mahwah, NJ: Erlbaum.

Corrigan, P. W., Kuwabara, S. A., \& O’Shaughnessy, J. (2009). The public stigma of mental illness and drug addiction: Findings from a stratified random sample. Journal of Social Work, 9, 139147. doi: $10.1177 / 1468017308101818$

Crawford, E. R., LePine, A., \& Rich, B. L. (2010). Linking job demands and resources to employee engagement and burnout: A theoretical extension and meta-analytic test. Journal of Applied Psychology, 95, 864-848. doi: 10.1037/a0019364

De Hoog, A. H. B., \& Den Hartog, D. N. (2009). Neuroticism anbd locus of control as moderators of the relationships of charismatic and autocratic leadership with burnout. Journal of Applied Psychology, 94, 1058-1067. doi: 10.1037/a0016253

Devine, P. G., Monteith, M. J., Zuwernik, J. R., \& Elliot, A. J. (1991). Prejudice with and without compunction. Journal of Personality and Social Psychology, 60(6), 817-830.

Diestel, S., \& Schmidt, K.-H. (in press). Costs of simultaneous coping with emotional dissonance and self-control demands at work: Results from two German samples. Journal of Applied Psychology. doi: 10.1037/a0022134

Dovidio, J. F., Kawakami, K., \& Beach, K. R. (2001). Implicit and explicit attitudes: Examination of the relations between measures of intergroup bias. In R. Brown \& S. Gaertner (Eds.), Blackwell handbook of social psychology: Intergroup processes (pp. 175-197). Oxford: Blackwell.

Garb, H. (1997). Race bias, social class bias and gender bias in clinical judgment. Clinical Psychology: Science and Practice, 4, 99-120. doi: 10.1111/j.1468-2850.1997.tb00104.x

Gil-Monte, P. R. (2008). Magnitude of relationship between burnout and absenteeism: A preliminary study. Psychological Reports, 102, 465-468. doi: doi: 10.2466/pr0.102.2.465-468 
Green, A. R., Carney, D. R., Pallin, D. J., Ngo, L. H., Raymond, K. L., Iezzoni, L. I., et al. (2007). Implicit bias among physicians and its prediction of thrombolysis decisions for black and white patients. Journal of General Internal Medicine. doi: 10.1007/s11606-007-0258-5

Greenwald, A. G., McGhee, D. E., \& Schwartz, J. L. K. (1998). Measuring individual differences in implicit cognition: The implicit association test. Journal of Personality and Social Psychology, 74(6), 1464-1480.

Hausknecht, J. P., Hiller, N. J., \& Vance, R. J. (2008). Work-unit absenteeism: Effects of satisfaction, commitment, labor market conditions, and time. Academy of Management Journal, 51(6), 1223-1245.

Hofmann, W., Gawronski, B., Gschwendner, T., Le, H., Schmitt, M. (2005). A meta-analysis on the correlation between the Implicit Association Test and explicit self-report measure.

Personality and Social Psychology Bulletin, 31, 1369-1385. doi:

$10.1177 / 0146167205275613$

Hystad, S. W., Eid, J., \& Brevik, J. I. (2011). Effects of psychological hardiness, job demands, and job control on sickness absence: A prospective study. Journal of Occupational Health Psychology, 16, 265-278. Doi: 10.1037/a0022904

Irwin, L. (2007). Homophobia and heterosexism: Implications for nursing and nursing practice. Australian Journal of Advanced Nursing 25(1), 70-76.

Judge, T. A., \& Chandler, T. D. (1996). Individual-level determinants of employee shirking. Industrial Relations, 51(3), 468-486.

Karpinski, A., \& Steinman, R. B. (2006). The single category implicit association test as a measure of implicit social cognition. Journal of Personality and Social Psychology, 91, 16-32. doi: 10.1037/0022-3514.91.1.16

Kehr, H. (2004). Implicit/explicit motive discrepancies and volitional depletion among managers. Personality and Social Psychology Bulletin, 30, 315-327. doi: 10.1177/0146167203256967 
Knudsen, H. K., Ducharme, L. J., \& Roman, P. M. (2009). Turnover intention and emotional exhaustion "at the top": Adapting the job demands-resources model to leaders of addiction treatment organizations. Journal of Occupational Health Psychology, 14, 84-95. doi: 10.1037/a0013822

Lambert, E. G., Hogan, N. L., \& Altheimer, I. (2010). An exploratory examination of the consequences of burnout in terms of life satisfaction, turnover intent, and absenteeism among private correctional staff. Prison Journal, 90, 94-114. doi: 10.1177/0032885509357586

Nosek, B. A. (2005). Moderators of the relationship between implicit and explicit evaluation. Journal of Experimental Psychology: General, 134, 565-584. doi: 10.1037/00963445.134.4.565.

Peris, T. S., Teachman, B. A., \& Nosek, B. A. (2008). Implicit and explicit stigma of mental illness. Journal of Nervous and Mental Disease, 196, 752-760. doi: 10.1097/NMD.0b013e3181cc43b5 Perugini, M., Richetin, J., \& Zogmaister, C. (2010). Prediction of behavior. In B. Gawronski \& K. Payne (Eds.), Handbook of implicit social cognition: Measurement, theory, and applications (pp. 255-277). New York, NY: Guilford Press.

Perugini, M., Richetin, J., \& Zogmaister, C. (in press). The formation of implicit and explicit attitudes for neutral and valenced stimuli using the self. Learning and Motivation.Petty, R. E., \& Briñol, P. (2009). Implicit ambivalence: A meta-cognitive approach. In R. E. Petty, R. H. Fazio \& P. Briñol (Eds.), Attitudes: Insights from the new implicit measures (pp. 119-164). New York, NY: Psychology Press.

Petty, R. E., Briñol, P., \& DeMarree, K. G. (2007). The meta-cognitive model (MCM) of attitudes: Implications for attitude measurement, change, and strength. Social Cognition, 25, 657-686. Phills, C. E.; Kawakami, K.; Tabi, E.; Nadolny, D.; Inzlicht, M. (2011). Mind the gap: Increasing associations between the self and blacks with approach behaviors. Journal of Personality and Social Psychology, 100, 197-210. doi: 10.1037/a0022159 
Rudman, L. A. (2004). Sources of implicit attitudes. Current Directions in Psychological Science, 13, 79-82. doi: 10.1111/j.0963-7214.2004.00279.x

Rudman, L. A., Phelan, J. E., \& Heppen, J. B. (2007). Developmental sources of implicit attitudes. Personality and Social Psychology Bulletin, 33, 1700-1713. doi: 0.1177/0146167207307487

Rydell, R. J., \& Durso, G. R. O. (2012). Can I borrow a feeling? Spillover of negative arousal from inconsistent information during attitude formation diminishes perceptions of well-being. Journal of Experimental Social Psychology, 48, 575-578. doi: 10.1016/j.jesp.2011.10.018

Rydell, R. J., McConnell, A. R., \& Mackie, D. M. (2008). Consequences of discrepant explicit and implicit attitudes: Cognitive dissonance and increased information processing. Journal of Experimental Social Psychology, 44, 1526-1532. doi: 10.1016/j.jesp.2008.07.006

Rydell, R. J., \& McConnell, A. R. (2010). Consistency and inconsistency in implicit social cognition: The case of implicit and explicit measures of attitudes. In B. Gawronski \& B. K. Payne (Eds.), Handbook of implicit social cognition (pp. 295-310). New York, NY: Guilford Press.

Rydell, R. J., McConnell, A. R., \& Mackie, D. M. (2008). Consequences of discrepant explicit and implicit attitudes: Cognitive dissonance and increased information processing. Journal of Experimental Social Psychology, 44, 1526-1532. doi: 10.1016/j.jesp.2008.07.006

Schulze, B. (2007). Stigma and mental health professionals: A review of the literature. International Review of Psychiatry, 19(2), 137-155.

Scoppa, V. (2010). Worker absenteeism and incentives: Evidence from Italy. Managerial and Decision Economics, 31, 503-515. doi: 10.1002/mde.1504

Strack, F., \& Deutsch, R. (2004). Reflective and impulsive determinants of social behavior. Personality and Social Psychology Review, 3, 220-247.

Teachman, B., Gapinski, K., Brownell, K., Rawlins, M., \& \& Jeyaram, S. (2003). Demonstrations of implicit anti-fat bias: The impact of providing causal information end evoking empathy. Health Psychology, 22, 68-78. doi: 10.1037/0278-6133.22.1.68 
van Breukelen, W., van der List, R., \& Steensma, H. (2004). Voluntary employee turnover: Combining variables from the "traditional" turnover literature with the theory of planned behavior. Journal of Organizational Behavior, 25, 893-914. doi: 10.1002/job.281

von Hippel, W., Brener, L., \& von Hippel, C. (2008). Implicit prejudice toward injecting drug users predicts intentions to change jobs among drug and alcohol nurses. Psychological Science, 19. 7-11. doi: 10.1111/j.1467-9280.2008.02037.x

Wahl, O., \& Aroesty-Cohen, E. (2010). Attitude of mental health professionals about mental illness: A review of the literature. Journal of Community Psychology, 38, 49-62. doi: 10.1002/jcop.20351

Yaniv, G. (1995). Burnout, absenteeism, and the overtime decision. Journal of Economic Psychology, 16, 297-309. doi: 10.1016/0167-4870(95)00011-C

Ybema, J. F., Smulders, P. G. W., \& Bongers, P. M. (2010). Antecedents and consequences of employee absenteeism: A longitudinal perspective on the role of job satisfaction and burnout. European Journal of Work and Organizational Psychology, 19, 102-124. doi: $10.1080 / 13594320902793691$

Zogmaister, C. (2011). Consequences of implicit-explicit inconsistency. In M. Cadinu, S. Galdi, \& A. Maas (Eds.) Social perception cognition and language in honour of Arcuri (pp. 93-108). Padova, Italy: CLEUP. 
Table 1.

SC-IAT Block Sequence

\begin{tabular}{ccc}
\hline Block & Instructions & Number of \\
& & trials \\
\hline
\end{tabular}

\begin{tabular}{lll}
\hline 1. Practice & Press the E key when a positive word or a word that refers to drug 24
\end{tabular}

block \# 1 addiction appears. Press the I key when a negative word appears.

\begin{tabular}{lll}
\hline 2. Critical & Press the E key when a positive word or a word that refers to drug & 72
\end{tabular}

block \# 1 addiction appears. Press the I key when a negative word appears.

3. Practice Press the E key when a positive word appears. Press the I key when a 24

block \# 2 negative word or a word that refers to drug addiction appears.

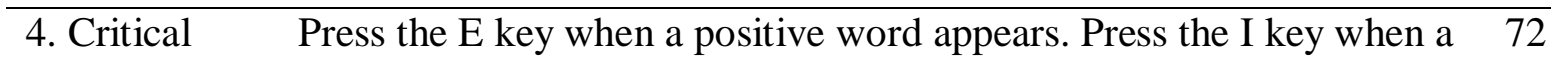

block \# 2 negative word or a word that refers to drug addiction appears. 
Table 2.

Demographic Details of the Sample.

\begin{tabular}{|l|c|c|c|c|}
\hline & $\begin{array}{c}\text { Percentage of } \\
\text { women }\end{array}$ & Age & Years of work & $\begin{array}{c}\text { Percentage of } \\
\text { former drug }\end{array}$ \\
& & & with drug-addicts & addicts \\
\hline Laypeople $(n=$ & $53.3 \%$ & $M=39.73$ & n.a. & \\
\hline Volunteers $(n=$ & $29.6 \%$ & $M D=15.43$ & n.a. & $48.2 \%$ \\
27) & & $S D=15.04$ & & $0 \%$ \\
\hline Practitioners $(n=$ & $60.0 \%$ & $M=40.80$ & $M=9.93$ & \\
\hline 30$)$ & & $S D=6.91$ & $S D=6.03$ & \\
\hline
\end{tabular}


Table 3.

Mean Implicit and Explicit Attitude Scores, Depending on Experimental Condition

\begin{tabular}{lccc}
\hline & $N$ & Explicit attitude & Implicit attitude \\
\hline Laypeople & 30 & $-1.00(.79)$ & $-.34(.90)$ \\
& & & $.21(.99)$ \\
\hline Practitioners & 27 & $.40(.44)$ & $.14(1.03)$ \\
\hline Volunteers & 30 & $.67(.77)$ &
\end{tabular}

Note: Standard deviations between parentheses 
Table 4.

Prediction of Explicit Attitude towards Drug Addicts

\begin{tabular}{|c|c|c|c|c|}
\hline Steps & Predictors & $\bar{b}$ & SE & $\Delta R^{2}$ \\
\hline \multirow[t]{2}{*}{$1 \mathrm{st}$} & Constant & $.387 * * *$ & .078 & \multirow{2}{*}{$.198 *$} \\
\hline & Implicit attitude & $.191 *$ & .077 & \\
\hline \multirow[t]{3}{*}{ 2nd } & Constant & $.381 * * *$ & .076 & \multirow{3}{*}{.079} \\
\hline & Implicit attitude & $.225 * *$ & .077 & \\
\hline & Years of experience with drug addicts (standardized score) & .128 & .079 & \\
\hline \multirow[t]{4}{*}{ 3rd } & Constant & $.435 * * *$ & .074 & \multirow{4}{*}{$.136^{*}$} \\
\hline & Implicit attitude & $.209 * *$ & .072 & \\
\hline & Years of experience with drug addicts (standardized score) & .089 & .075 & \\
\hline & Implicit attitude $\mathrm{x}$ Years of experience with drug addicts & $.185 *$ & .080 & \\
\hline
\end{tabular}


Table 5.

Prediction of Absenteeism and Extra Work

\begin{tabular}{|c|c|c|c|c|c|c|c|}
\hline \multirow[b]{2}{*}{ Steps } & \multirow[b]{2}{*}{ Predictors } & \multicolumn{3}{|c|}{ Absenteeism } & \multicolumn{3}{|c|}{ Extra work } \\
\hline & & $\bar{b}$ & $S E$ & $\Delta R^{2}$ & $b$ & $\overline{S E}$ & $\Delta R^{2}$ \\
\hline \multirow[t]{3}{*}{$1 \mathrm{st}$} & Constant & -3.89 & 2.72 & \multirow{3}{*}{.14} & .73 & 2.34 & \multirow{3}{*}{.08} \\
\hline & Gender & .90 & .84 & & .43 & .69 & \\
\hline & Age & $.12 *$ & .06 & & .07 & .05 & \\
\hline \multirow[t]{5}{*}{ 2nd } & Constant & -4.14 & 2.89 & \multirow{5}{*}{.01} & -1.42 & 2.41 & \multirow{5}{*}{.08} \\
\hline & Gender & .99 & .93 & & .03 & .78 & \\
\hline & Age & .13 & .06 & & .08 & .05 & \\
\hline & Implicit attitude & -.22 & .48 & & .35 & .39 & \\
\hline & Explicit attitude & .55 & 1.00 & & .45 & .76 & \\
\hline \multirow[t]{4}{*}{ 3rd } & Constant & -4.55 & 2.56 & \multirow{6}{*}{$5.88 *$} & -1.53 & 2.18 & \multirow{6}{*}{$.19 *$} \\
\hline & Gender & 1.25 & .86 & & -.18 & .71 & \\
\hline & Age & $.14^{*}$ & .06 & & .08 & .05 & \\
\hline & Implicit attitude & .40 & .51 & & -.02 & .39 & \\
\hline & Explicit attitude & .64 & .91 & & .32 & .69 & \\
\hline & Implicit x explicit attitude & $-2.01 *$ & .83 & & $1.35^{*}$ & .60 & \\
\hline
\end{tabular}

Note. ${ }^{*} p<.05$. 


\section{Figure captions}

Figure 1. Interactive effects exerted by experience and implicit attitude on explicit attitude towards drug addicts (Low and high implicit attitude scores are considered at $M-1 S D$, and $M+1$ $S D$, respectively).

Figure 2. Interactive effects exerted by explicit and implicit attitudes on absenteeism and extra work. (Low and high implicit attitude scores are considered at $M-1 S D$, and $M+1 S D$, respectively). 
Figure 1.

\section{Explicit attitude score}

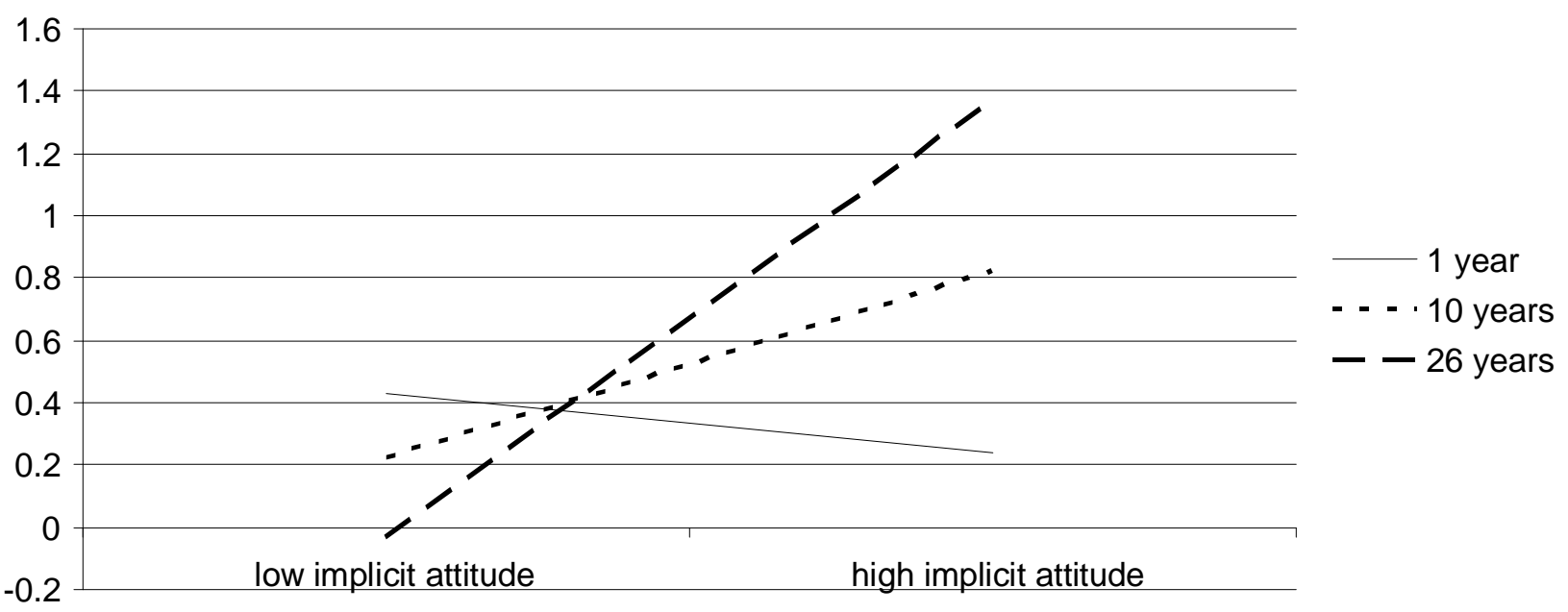


Figure 2.

\section{Predicted number of days of absence}

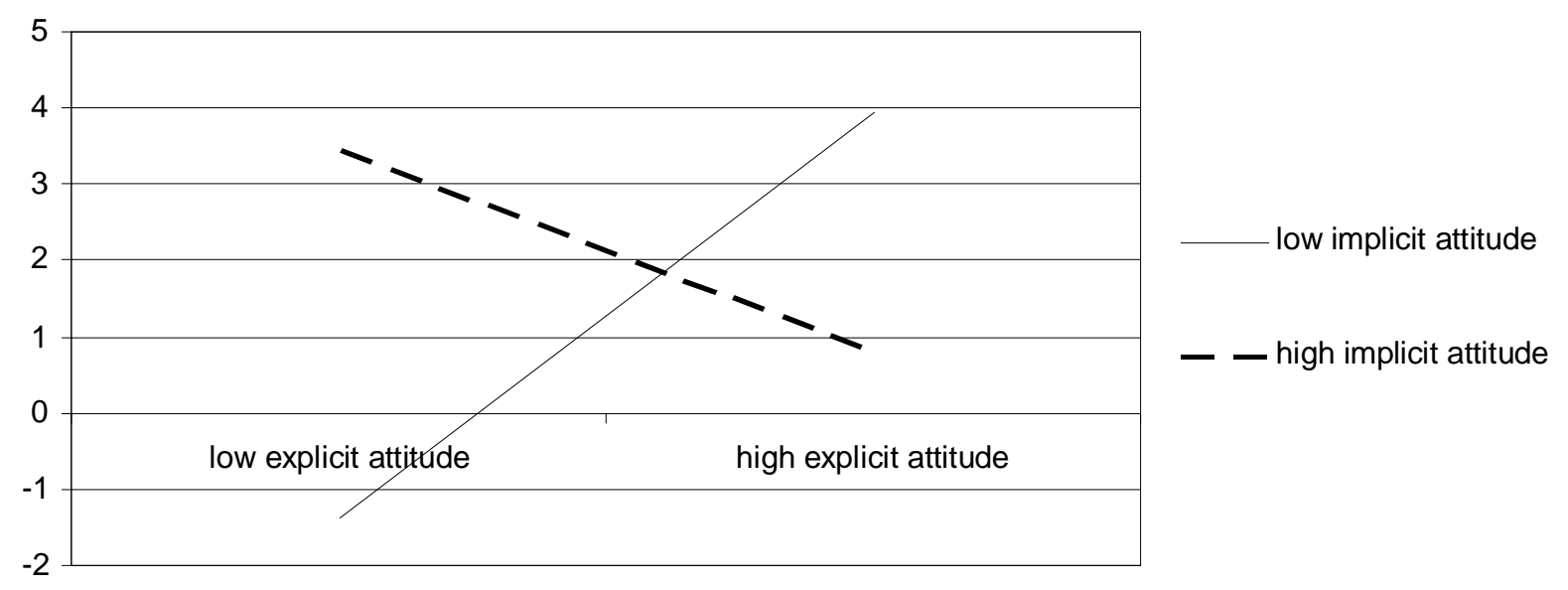

\section{Predicted number of days of extra work}

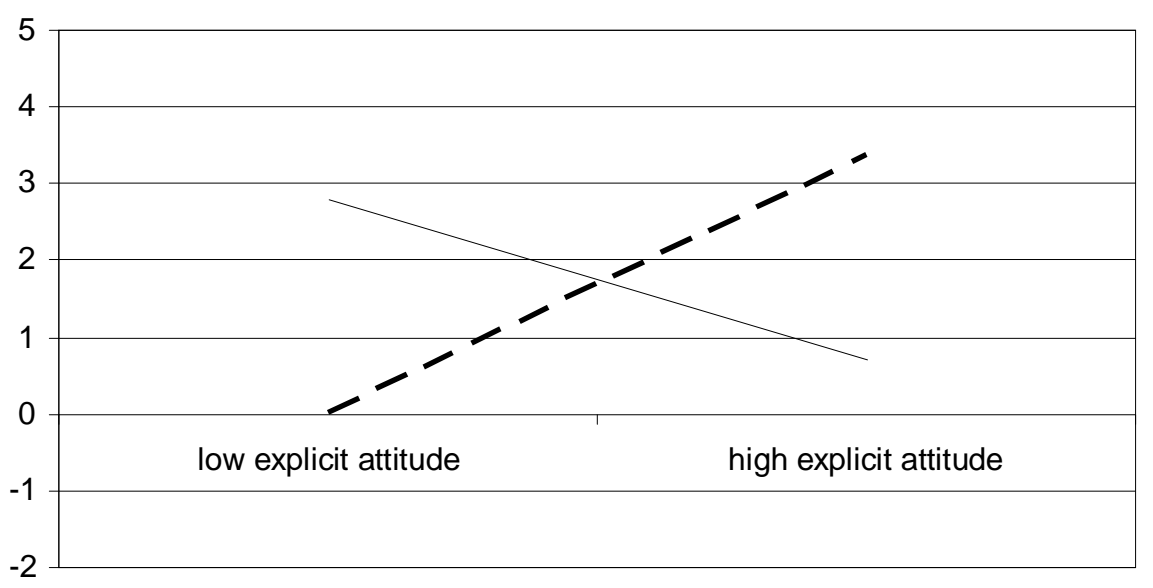




\section{Footnotes}

${ }^{1}$ We did not have similar expectations for the category of volunteers because this is a highly heterogeneous category, with approximately half of the volunteers in our sample being ex drug addicts, hence ex members of the stigmatized category, while the others were not ex drug addicts.

${ }^{2}$ We were interested both in the attitudes of people who had direct experience with people suffering with drug addiction and in the attitudes of laypeople who did not have such an experience. Therefore, we administered to laypeople a slightly modified version of the five items (e.g. "I feel patient when caring for patients who are addicted to drugs”) that made a direct reference to an experience they did not have, substituting the indicative with the conditional tense (e.g. "I would feel patient when caring for patients who are addicted to drugs”). The list of 15 items is available on request from the authors.

${ }^{3}$ In parallel analyses we kept this design effect under control with the following three steps. First, we divided our sample into two sub-samples, based on the order of presentation of the critical blocks. Second, we standardized the SC-IAT scores in each of the sub-samples. Third, we merged 
the two Sc-IAT scores thus obtained to compute a new score, free from the effect of the design variables. The results we obtained, available upon request, were almost identical to those we present.

${ }^{4}$ The same pattern of results (available upon request) emerged when we re-analyzed the data computing the indexes of inconsistency and direction following Kehr (2004). 